radius of "more than one hundred yards". There may well have been a similar error in saying that the CERN synchrotron cost $\$ 55$ million-nearly twice its real cost, in fact.

Another sort of error creeps in because the bulk of the book seems to have been written in 1966, or earlier, and only superficially revised. On page 8 , for example, we are told that there are at CERN "more than two thousand people" and its "yearly cost (is) nearly $\$ 35$ million", figures which were true in 1965 . The real figures at the present time are 3,400 people (including visitors) and a yearly budget of $\$ 77$ million. I do not want to give the impression that there are many errors of this kind but those that there are are seriously misleading.

As I have said already, this book is not entirely without merit. The building of CERN and its contribution to high energy physics make a remarkable and inspiring record of human cooperation and achievement, and Jungk does give some impression of this, particularly in its early days. Nobody who has been privileged to be associated with CERN could fail to be moved in sorne way by its success. And again, the problems that such an enterprise throws up are serious and deserve considerable attention.

But it must be said that this book does not match in any way the splendid character of its subject. This is particularly unfortunate in that there is an urgent need for books which document science in such a way that all educated men can get some feeling for the way science is really done.

Oddly enough, there is not a single illustration in the book. A. W. MERRISON

\section{KEY MINERALS}

\section{Feldspars}

By Tom F. W. Barth. Pp. xi +261. (Wiley (Interscience): New York and London, May 1969.) 136s.

THIs ubiquitous group of rock-forming minerals has undoubtedly been the subject of more research than any other mineral group; their importance in the classification of rocks formed under a wide variety of geological conditions and the persistent and evolving problems that they present have made feldspars a fascinating study for generations of mineralogists, petrologists, geochemists and crystallographers alike; they do not yield up their secrets easily and there are many difficulties still to be resolved in spite of the quickening pace of research since the war, spurred on by each new experimental technique. It is against this background that Professor Barth, a pioneer in modern feldspar studies, has written this monograph in which he collects together many of the data so widely scattered through the literature; he wisely omits descriptions of determinative methods, but, inevitably, current theories and speculations must be interposed to delineate paths of research. The matcrial is presented in five chapters on general mineralogy and classification, pseudosymmetry and twinning, structures, physical and thermodynamic properties; a sixth chapter is really an interesting appendix on the history of feldspar elassification and terminology. It represents a formidable undertaking by the author who, conscious of the possibility of being overtaken by events, ruefully remarks in his preface that "still more information appeared while the book was in production which could only in part be incorporated in the present work". No doubt some of the ideas mentioned in the text will be jettisoned or revised by future work, but the value of many of the data (and the extensive lists of original references) is incontrovertible.

For a specialist reader it is interesting to see how someonc as experienced as the author views the present state of knowledge on the group as a whole; experts will always disagree and there will surely be those who will quarrel about the omissions, or the accentuations, or the interpretations in this treatment. Whatever the diversity of individual views, it is certain that fellow feldspar enthusiasts will admire the energy and wide understanding that stimulated the compilation of this monograph. For the non-specialist who wishes to keep abreast of the current feldspar tide the rewards of perseverance will be worthwhile; the style is terse, and even cryptic at times, but, aided by ample reference to the listed publications, its slow digestion will be both informative and indicative of the irresistible spell of the feldspars for their dedicated disciples.

The author is to be congratulated on the service he has performed for everyone who has more than a passing interest in the Earth sciences where the studies on these key minerals mark the pattern of future research on many other mineral systems. His book certainly deserves a place on institutional library shelves, and it will be a pity if the price deters too many individual purchasers who would benefit by its presence in their own collections.

Peter Gay

\section{Correspondence}

\section{Mycoplasms}

Sir,-The letter by Dr G. G. Tedeschi et al. (Nature, 222,1285 ; 1969) appears so blatantly open to criticism that in criticizing it perhaps one is entering a trap. The risk has to be taken. The authors found that nucleosides and amino-acids were incorporated in suspensions of human erythrocytes and suggested that this was due to incorporation into bacteria in their L-phase or mycoplasmas present in the suspensions. It is not the finding that I dispute but the interpretation. The authors stated that the features of incorporation of nucleosides and amino-acids into the erythrocyte suspensions were similar to those observed in incorporation into cultures of bacteria. Indeed, nowhere did they indicate that their blood samples were free of known bacteria. Even if one were to assume that this was so, is it scientifically sound to propose that the increasing incorporation observed on incubation of the "haemocultures" was due to the multiplication in the cultures of mycoplasma-like forms? The authors suspended the erythrocytes in Difco PPLO broth containing streptomycin, a medium not even conducive to the growth of the more easily grown mycoplasmas, let alone "mycoplasma-like" forms. If such forms were viable organisms, either mycoplasmas or L-forms, then their existence should have been demonstrated in the same blood samples as used for the biochemical studies. Furthermore, the biochemical results should not be used as confirmation of the presence of organisms which have not been demonstrated by either conventional or unconventional biological techniques. Because the authors prompted the idea, it is likely that the data presented will be seized as ammunition for the argument that bacterial organisms exist throughout the body in the $\mathrm{L}$-phase. The latter idea is unestablished, however, and it would seem unwise to attempt to support it by further contentious findings. Finally, I assume that the mycoplasms consistently referred to by the authors are equivalent to mycoplasmas. Is this the trap? Surely not.

Yours faithfully,

\section{TAYLOR-ROBINSON}

MRC Clinical Rescarch Centre,

Harvard Hospital,

Coombe Road,

Salisbury, Wiltshire. 